\title{
The Legacy of Political Violence across Generations 100
}

\author{
Noam Lupu Vanderbilt University \\ Leonid Peisakhin New York University-Abu Dhabi
}

\begin{abstract}
Does political violence leave a lasting legacy on identities, attitudes, and behaviors? We argue that violence shapes the identities of victims and that families transmit these effects across generations. Inherited identities then impact the contemporary attitudes and behaviors of the descendants of victims. Testing these hypotheses is fraught with methodological challenges; to overcome them, we study the deportation of Crimean Tatars in 1944 and the indiscriminate way deportees died from starvation and disease. We conducted a multigenerational survey of Crimean Tatars in 2014 and find that the descendants of individuals who suffered more intensely identify more strongly with their ethnic group, support more strongly the Crimean Tatar political leadership, hold more hostile attitudes toward Russia, and participate more in politics. But we find that victimization has no lasting effect on religious radicalization. We also provide evidence that identities are passed down from the victims of the deportation to their descendants.
\end{abstract}

Replication Materials: The data, code, and any additional materials required to replicate all analyses in this article are available on the American Journal of Political Science Dataverse within the Harvard Dataverse Network, at: http://doi.org/10.7910/DVN/VEPHLS.

tates regularly perpetrate violence against their inhabitants. ${ }^{1}$ A conservative official estimate puts the number of victims of Stalinist repressions at 3.8 million (Zemskov 1991), and an estimated 1.5 million people died in the countryside alone during China's Cultural Revolution (MacFarquhar and Schoenhals 2008). Moreover, state-sponsored and politically motivated violence against minority groups remains a defining feature of contemporary politics. These experiences profoundly shape how victims interact with the state and think about politics. Some become politically apathetic and withdraw from political activity (Benard 1994; Wood 2006), whereas others mobilize into collective action (Bellows and Miguel 2009). Many develop feelings of victimization and sensitivity to perceived threats as a result of these traumatic experiences (Canetti-Nisim et al. 2009). But how long do these effects last?
Political scientists have recently noted that political experiences can sometimes have long-lasting legacies. Institutions can affect politics long after they cease to exist (Acemoglu, Johnson, and Robinson 2001), and political identities formed in a particular historical moment can endure for decades (e.g., Darden and GrzymalaBusse 2006; Lupu and Stokes 2010; Wittenberg 2006). But these legacies are often thought to be transmitted through persistent institutions, economic structures, or religious communities. Might experiences of political violence similarly leave lasting legacies? And if so, might they be passed down through families from generation to generation, as suggested by some theories of value transmission (Bisin and Verdier 2000, 2001)?

Answering this question poses empirical challenges. Victims of political violence are typically targeted because of their group membership, political attitudes, or

Noam Lupu is Associate Professor of Political Science, Vanderbilt University, Commons Center, PMB 0505, 230 Appleton Place, Nashville, TN 37203 (noam.lupu@vanderbilt.edu). Leonid Peisakhin is Assistant Professor of Political Science, New York University - Abu Dhabi, NYUAD, A5-149, P.O. Box 903, New York, NY 10276-0903 (leonid.peisakhin@nyu.edu).

For their comments and advice, we thank Laia Balcells, Natalia Bueno, Geoff Dancy, Evgeny Finkel, Scott Gehlbach, Ted Gerber, Francesca Grandi, Lynn Hancock, Evan Lieberman, Kyle Marquardt, Kristin Michelitch, Monika Nalepa, Richard Niemi, Ellie Powell, Jonathan Renshon, Luis Schiumerini, Nadav Shelef, Matt Singer, Scott Straus, Josh Tucker, Jason Wittenberg, Libby Wood, three anonymous reviewers at the AJPS, and seminar participants at American, GW, MIT, NYU-Abu Dhabi, Pontifical Catholic University in Chile, Di Tella, ITAM, Vanderbilt, Wisconsin, and Yale. Rachel Schwartz provided excellent research assistance. This research was approved by Institutional Review Boards at New York University-Abu Dhabi and University of Wisconsin-Madison. All translations are our own.

${ }^{1}$ We use the term political violence to refer to violence caused by political actors.

American Journal of Political Science, Vol. 61, No. 4, October 2017, Pp. 836-851

(C)2017, Midwest Political Science Association

DOI: $10.1111 /$ ajps.12327 
behaviors. This makes it difficult for researchers to identify whether the distinctive attitudes and behaviors of victims of political violence are caused by their victimization. In addition, victims' descendants may themselves be targets of further political violence. As a result, it may be difficult to discern whether the descendants of victims hold particular attitudes because of their ancestors' experiences or because of their own victimization.

This article overcomes these challenges by studying the Crimean Tatars, a minority Muslim population in Crimea. We study the legacy of political violence that took place during the Crimean Tatars' deportation from their homeland to Central Asia in 1944. Between onefifth and one-half of the deportees perished within a year of resettlement because of rampant infectious diseases, starvation, and squalor. Although all Crimean Tatars suffered the violence of deportation, some lost more family members along the way. Losing a relative during and immediately after deportation is, we argue, an instance of the broader phenomenon of state-sponsored repression. Our analysis leverages variation in this additional violence, which we demonstrate was not politically targeted. The grandchildren of the deportees were born mostly after the collapse of the Soviet Union and once their families had returned to Crimea, then part of Ukraine. The fact that they had little to no interaction with the Soviet state helps us to isolate the effect of family socialization.

We argue that political violence shapes the core identities of its victims, generating ethnic parochialism, and that these psychological responses are transmitted from parent to child, informing their contemporary political attitudes and behaviors. To test this, we conducted a multigenerational survey of Crimean Tatar families living in Crimea in 2014. We interviewed three generations of respondents in 300 families. To our knowledge, this is the first multigenerational survey on the legacies of political violence, and one of very few such surveys ever conducted in the developing world. Whereas prior studies rely on respondents' accounts of the violence suffered by their ancestors (Balcells 2012; Grosjean 2014), this design allows us to measure an ancestor's exposure to violence as related by the survivors themselves.

Consistent with our expectations, we find that the descendants of survivors who were exposed to more violence are more likely to self-identify as victims, be more fearful of potential threats, and have higher levels of ingroup attachment. They also take stronger political positions in favor of Crimean Tatars, are more hostile toward Russia, ${ }^{2}$ and participate more in politics. Contrary to some

${ }^{2}$ Technically, the perpetrator of the violence was the Soviet state. From the perspective of minority nationalities, the Soviet Union studies of victims, we find no intergenerational effect of victimization on radicalization or religiosity. To probe the mechanisms by which these effects are transmitted across generations, we offer suggestive evidence that victimization affects the identities of first-generation respondents and that they transmit these through the family to their children and grandchildren.

\section{Violence, Historical Legacies, and Family Socialization}

Violence has powerful consequences for politics. Wartime violence may break down social institutions and lock countries into conflict traps (Walter 2004). Whereas some scholars argue that violence fragments communities and damages social cohesion (Walter and Snyder 1999), others find that violence can force communities to overcome differences (Bellows and Miguel 2009; Fearon, Humphreys, and Weinstein 2009; Gilligan, Pasquale, and Samii 2014).

In the last decade or so, scholars have begun to study how violence affects individual political behavior and attitudes. The balance of findings suggests that victims of political violence become more resilient and more politically engaged (Blattman 2009; Wood 2003), although the empirical record is mixed (Balcells 2012; Benard 1994; Grossman, Manekin, and Miodownik 2015). In a recent meta-analysis, Bauer et al. (2016) find substantial evidence that exposure to wartime violence increases prosocial behavior. They also find suggestive evidence that this prosocial behavior is biased toward ingroups. However, few studies define ingroups and outgroups consistently. Whether violence induces ethnic parochialism remains an important open question; if it does, it could help explain why countries fall into cycles of repeated civil conflict.

Psychologists have documented extensively why exposure to violence might affect political attitudes and behavior. Traumatic experiences are linked to psychological disorders like depression, anxiety, and posttraumatic stress (e.g., Hobfoll, Cannetti-Nisim, and Johnson 2006; Johnson and Thompson 2008). By heightening victims' fears of future threats from the perpetrator, traumatic experiences often also engender stronger ingroup attachments, hostile and exclusionist attitudes toward outgroups, and self-identities as victims (Beber, Roessler, and Scacco 2014; Berrebi and Klor 2008; Canetti-Nisim et al. 2009; Cassar, Grosjean, and Whitt 2013). These effects, in turn, shape victims' attitudes about transitional

promoted the interests of ethnic Russians. Russia's leaders also foster the view of post-1991 Russia as a successor to the Soviet Union. 
justice and reconciliation after conflicts (Nalepa 2012). Scholars have also argued that in some circumstances, victimization fosters religiosity (Chen and Koenig 2006). In other cases, it appears to induce radicalization and extreme hostility toward the perpetrator (Horgan 2008; McCauley and Moskalenko 2008).

Most research on the individual-level effects of violence focuses exclusively on the survivors of political violence themselves, typically shortly after their victimization and sometimes while violent conflicts are ongoing (Bauer et al. 2016). Yet, there are good reasons to expect that exposure to violence would affect victims' descendants too (see Rozenas, Schutte, and Zhukov 2017). Indeed, recent studies have demonstrated that political attitudes associated with certain institutional practices persist long after the institutions themselves have disappeared (Darden and Grzymala-Busse 2006; Nunn and Wantchekon 2011; Peisakhin 2012; Wittenberg 2006).

Among the least understood areas of research on violence are the social legacies of conflict (Blattman and Miguel 2010). Very few studies examine the intergenerational effects of political violence on political attitudes and behaviors. In Spain, Balcells and colleagues (Aguilar, Balcells, and Cebolla-Boado 2011; Balcells 2012) find a correlation between ancestor victimization and both political identities and attitudes regarding transitional justice, but no relationship with political participation. Grosjean (2014) finds that Europeans with ancestors killed or wounded in wars exhibit lower levels of trust and diminished belief in the efficacy of national political institutions. Psychologists have also widely documented posttraumatic psychological disorders among the descendants of war veterans and Holocaust survivors (e.g., LevWiesel 2007; Weiss and Weiss 2000). Yet, these studies rely on respondents' accounts of the violence suffered by their ancestors, with obvious potential for bias. They also focus on violence that may have been politically targeted, making it difficult to isolate the effect of violence. We improve upon this by studying violence that was not politically targeted and by measuring victimization as it is reported by the generation of survivors themselves.

Research on intergenerational legacies also rarely demonstrates how identities, attitudes, and behaviors are passed down from generation to generation. Studies of historical legacies sometimes hypothesize family socialization (Nunn and Wantchekon 2011; Voigtländer and Voth 2012), but they rely on aggregate data that measure outcomes for localities or entire regions. As a result, most existing studies cannot rule out the possibility that local institutions or communal networksrather than families-sustain the observed legacies. On the other hand, survey data have shown how family socialization shapes certain political views, but these studies focus almost exclusively on partisan and religious identities in advanced democracies (Bisin, Topa, and Verdier 2004; Jennings and Niemi 1981; Jennings, Stoker, and Bowers 2009; Zuckerman, Dasovic, and Fitzgerald 2007). Instead, this article focuses on a broader set of political identities-and their associated attitudes and behaviors-in a semi-authoritarian and less developed context. Our research design and multigenerational survey allow us to better isolate the effect of family socialization.

\section{Hypotheses}

Building upon prior research on the effects of violence, we expect that violence experienced by first-generation respondents in our study (i.e., those who themselves experienced the deportation) induced them to identify more strongly with their ethnic group and as victims made them more hostile toward outgroups, especially the perpetrator, and instilled a more acute fear of possible future threats. More specifically, we expect something like a monotonic relationship between exposure to violence and changes in political identities. This follows directly from findings in psychology and political science that individuals exposed to more violence exhibit more pronounced effects (Blattman 2009; Johnson and Thompson 2008).

Just as families socialize partisan and religious identities, we expect parents to also transmit ethnic and political identities to their children. On the one hand, this means that the effects of political violence will persist across generations, consistent with studies of historical legacies, but with the locus of transmission being the family. On the other hand, theories of intergenerational transmission highlight that the family often competes with other sources of socialization, such as formal education or social groups (Bisin and Verdier 2000, 2001). We therefore also expect that the legacies of violence transmitted through the family will diminish across generations.

Finally, we expect inherited political identities to inform the contemporaneous political attitudes and behaviors of the descendants of survivors. Parents may directly socialize some specific political attitudes and behaviors in their children, but most of the socialization effect is likely indirect, mediated through the transmission of identities. This is most likely when the political context changes, as it did, dramatically, for the Crimean Tatars. Political engagement, for instance, was all but irrelevant for the survivors themselves, living in the Soviet Union. But for their grandchildren, who came of age in independent Ukraine, an inherited ethnic identity likely induces political participation as a defense mechanism to protect their 
social group. ${ }^{3}$ We anticipate that the intergenerational effects of violence on political identities in turn shape the contemporary attitudes and behaviors of descendants.

\section{Evidence from Crimean Tatars}

Over the course of May 18-20, 1944, days after the Soviet Union recaptured the Crimean Peninsula from Nazi Germany, the Red Army deported all Crimean Tatars (a population of roughly 190,000) mostly to Uzbekistan on charges of collaborating with the Nazis (Bugai 2004; Williams 2016). ${ }^{4}$ Deportation came as a complete surprise to Crimean Tatars, who had no prior warning from the authorities. Families were given 10-15 minutes to collect what few belongings they could carry by hand, often in the middle of the night (Aleshka et al. 2010). As one Soviet officer recalled, "people became flustered, grabbed unnecessary things and we pushed them with our rifles toward the exit" (quoted in Uehling 2004, 89).

The journey in cattle trains from Crimea to Central Asia lasted 3 weeks (Bekirova 2004, 30). Food and water were scarce, sanitary conditions were abysmal, and diseases spread quickly. According to official estimates, several thousand deportees perished in transit, mainly from starvation, dehydration, and infectious diseases (Williams 2016). ${ }^{5}$ An estimated 16,000 more deportees died in the first 6 months in Central Asia. Government statistics report that about $20 \%$ of Crimean Tatar deportees perished in 1944-45 (Bugai 2002, 114). In contrast, data collected by Crimean Tatar activists in the 1960s suggest that $46 \%$

${ }^{3}$ Here, we depart from prior studies. Balcells (2012) finds no effect of ancestor violence on political participation; Blattman (2009) does, but argues that violence induces engagement as a result of posttraumatic growth.

${ }^{4}$ NKVD (People's Commissariat for Internal Affairs) troops were stationed in every Crimean Tatar village several days beforehand, and NKVD operatives had the residential addresses of Crimean Tatar families reconfirmed in ethnically mixed villages and in urban centers. Table A1 in the supporting information lists the location of Crimean Tatars in 1953; the vast majority (roughly 80\%) had been deported to Uzbekistan. In our sample, $86 \%$ of first-generation respondents said they had been deported to Uzbekistan, and another $4 \%$ to other Central Asian Republics (Kazakhstan and Tajikistan). Only $10 \%$ of our respondents spent deportation in Russia, under somewhat different conditions. Excluding them from our analysis does not substantively change our results (Table A12).

${ }^{5}$ Most deportees were loaded onto trucks to take them from their village to the train depots. The vast majority of the trains went to Tashkent, and deportees were sent on to different Uzbek provinces from there (Williams 2016). We found no statistically significant relationship between the region our first generations were deported from and the intensity of their victimization (Table A5). We also found no statistically significant associations between the republic they were deported to and victimization (Table A6). of the Crimean Tatar population died during or right after deportation (Bekirova 2004).

According to Bekirova (2004, 31), "Those who survived the first years of exile report that these years were the hardest. Witness accounts are remarkably uniform and differ only with regard to minor detail. Commonalities are many-constant unbearable hunger, illnesses (malaria, dysentery, typhus), exhausting labor, and deaths." Conditions for Crimean Tatars were so poor that even local Soviet officials complained to their superiors. Health officials in Tashkent wrote to Uzbekistani authorities in December 1944:

People were housed in stables, barns, dugouts, and other unsuitable quarters.... From the outset, [their] diet was unbalanced with regards to content and insufficient as to calories. Over the course of June-September [they] received eight kilograms of flour per person [per month]. No fats or proteins were consumed. (quoted in Gabrielian et al. 1998, 68)

Eventually, Crimean Tatars moved into more permanent housing and began to participate in the local economy. Until 1956, they were not permitted to leave their settlements without authorization and were surveilled heavily. They were also prohibited from returning to Crimea until 1989 and subjected to professional discrimination throughout the Soviet period (Bugai 2004).

The Stalinist repressive system did not single out individuals within the Crimean Tatar community for deportation or especially harsh treatment; rather, the whole ethnic group was deported wholesale and placed in similarly harsh conditions. There were hardly any exceptions. Even the former head of Yalta's party committeeone of the most senior Crimean Tatar communists-was not permitted to return to Crimea (Bekirova 2004, 41). Red Army veterans were treated the same way as suspected Nazi collaborators. ${ }^{6}$ Indeed, some Crimean Tatar Red Army soldiers were fighting at the front while their relatives were deported. When the war ended, about 9,000 demobilized soldiers (including 524 officers and 1,392 sergeants) were sent to Central Asia to join their families (Williams 2016).

Crimean Tatar families also experienced a massive disruption when it came to material wealth. Deportation thrust all Crimean Tatars-regardless of wealth, education, or political leanings-into equally harsh conditions. Upon arrival in Central Asia, all Crimean Tatars were

${ }^{6}$ In our survey, $86 \%$ of first-generation respondents said that they had a family member who had served either in the Red Army or in Soviet partisan battalions. 
equally destitute. This meant that little, if any, material wealth could be transferred across generations.

At the collapse of the Soviet Union in 1991, Crimea became an autonomous republic within independent Ukraine. Reputable estimates suggest that roughly $90 \%$ of Crimean Tatars returned to Crimea by the early 2000s (Zaloznaya and Gerber 2012). ${ }^{7}$ The 277,000 Crimean Tatars living in Crimea in 2012 made up about $12 \%$ of the Peninsula's population.

In March 2014, the Russian government seized upon political instability in Ukraine and occupied Crimea. Within days, Russia held a referendum on annexing the Peninsula and won overwhelming support. In September 2014, elections for the new Crimean Parliament were held in which Russia's ruling political party won over $90 \%$ of the seats.

Virtually all Crimean Tatars had been deported to Central Asia in 1944, but some suffered more intense violence than others. Some lost family members either during the deportation or shortly thereafter to starvation or disease. Historical accounts suggest that this variation within the population of deportees was unrelated to politics (Bekirova 2004; Bugai 2004; Uehling 2004). The elderly and the infirm would have been more susceptible to disease. But particularly in the early years in which deportees lived in inadequate housing at close quarters, infectious diseases would have spread in nonsystematic ways (Mollison 1995). There is no reason to think that death from starvation or disease was correlated with ideological or religious convictions, and there is a strong case to be made that assignment of the violence of a family member's death was exogenous to people's existing attitudes and behaviors. This means that we can make causal inferences about the effects of this particular type of violence, ${ }^{8}$ even though all Crimean Tatars suffered the violence of deportation. Although death from disease and malnutrition can be thought of as indirect violence, our fieldwork made it very clear that Crimean Tatars without any hesitation assign responsibility for it to Soviet authorities.

Another methodological advantage of studying this particular population is that the grandchildren of living Crimean Tatars who personally experienced deportation have themselves had little or no interaction with the

${ }^{7}$ In a pilot survey we conducted in July 2014 , only $4 \%$ of respondents said they had relatives who had stayed behind in Central Asia.

${ }^{8}$ Spillover effects in this population are very likely: People who witnessed the deaths of other Crimean Tatars' relatives were likely themselves affected by that experience. Such spillovers should diminish the differences in our sample between those who lost their own relatives and those who did not, making it harder to detect the kinds of effects we do uncover.
Soviet state. ${ }^{9}$ This means that the fact that their grandparents had been victimized is unlikely to have affected their own personal interactions with politics. They were not themselves targeted by the state for further victimization because their ancestors had been more victimized. ${ }^{10}$ As a result, any relationships we uncover between the victimization of their ancestors and their own identities, attitudes, or behaviors are likely the result of family socialization. ${ }^{11}$

\section{The Survey}

We conducted a face-to-face, multigenerational survey of Crimean Tatars living in Crimea between November 2014 and January 2015. We began with a stratified sample of Crimean settlements in which at least $10 \%$ of the population was Crimean Tatar. Interviewers randomly sampled households until they found a Crimean Tatar respondent over 73 years old, meaning he or she was at least 3 years old at the time of the deportation. ${ }^{12}$ After interviewing each first-generation respondent, we followed the family chain down. ${ }^{13}$ Within each family, two

${ }^{9}$ Half of our sample of third-generation respondents was born after the collapse of the Soviet Union, and another $45 \%$ was less than 10 years old when the Soviet Union ceased to exist. Limiting our analysis to only those born after the Soviet Union's collapse does not substantively change our results (Table A13).

${ }^{10}$ Crimean Tatars were subjected to discrimination or harassment under Ukrainian authorities as well. However, there is no reason to think that Ukrainian authorities specifically targeted Crimean Tatars whose ancestors suffered more intense violence during and shortly after deportation.

${ }^{11} \mathrm{~A}$ possible alternative is that more victimized families cluster together upon returning to Crimea, but Table A5 shows little evidence of this. After the collapse of the Soviet Union, Crimean Tatar media and Ukrainian schooling discussed the deportation, undoubtedly helping to preserve awareness among the younger generation. But this too cannot account for variation since all young Crimean Tatars were equally exposed to these messages.

${ }^{12}$ Research in psychology has shown that children are especially traumatized by violence (Bauer et al. 2014), suggesting that our first-generation respondents-relatively young at the time of the deportation-might have been especially affected by the loss of relatives. In future studies, we intend to focus on more recent violence to see whether we find similar effects among adults.

${ }^{13}$ One could imagine how this unavoidable sequencing might have primed responses. But our results are consistent when we limit our sample to families who do not live in the same settlement (Table A15) or those interviewed on the same day (Table A16), within one day of each other (Table A17), or within two days of each other (Table A18). Both geographic distance and temporal proximity make it less likely that grandparents primed their grandchildren after they took our survey. 
second-generation respondents were randomly selected, and subsequently two children of every secondgeneration respondent were also picked at random. The enumerators visited second- and third-generation respondents at their places of residence. Our final sample consists of 300 first-generation respondents, 600 secondgeneration respondents, and 1,004 third-generation respondents living in 23 towns and 191 villages across Crimea. The survey is thus representative of Crimean Tatar families currently residing in Crimea with at least one living survivor of the deportation. ${ }^{14}$

Our survey took place 6 months after the annexation of Crimea by Russia. We had to postpone our initial planned fieldwork because of the Kyiv protests and subsequent events in late 2013. There is no way to know whether these events amplified the effects of deportation-era violence on current identities, attitudes, and behaviors; we revisit this issue in the concluding section. Although the conflict with Russian security forces in Crimea was shortlived, we were concerned about Crimean Tatars' being reluctant to answer political questions. To address this concern, we hired and trained ethnic Crimean Tatar enumerators, and we offered respondents a choice of survey instruments in Russian or Crimean Tatar. During pilot surveys conducted in July and October 2014, we found that respondents seemed comfortable sharing their deportation experiences and political opinions with Crimean Tatar interviewers, even when we were present. Still, we devised indirect questions to capture especially sensitive issues, such as support for radical Islam.

\section{Measuring the Legacies of Violence}

Our primary independent variable of interest is violent victimization during and shortly after the 1944 deportation. We asked our first-generation respondents, "Did any of your family members ${ }^{15}$ die during the train journey to the deportation location or immediately after in 19441945 because of poor conditions?" We recorded whether respondents said no members of their family had died, one person had died, two or three relatives had died, or

\footnotetext{
${ }^{14}$ The supporting information provides further details on sampling, sample characteristics by generation (Table A2), and descriptive statistics (Table A3).

${ }^{15}$ In Russian and Crimean Tatar, this implies close relatives: parents and grandparents, their siblings, and the respondent's own siblings. We did not ask respondents which relatives died. It is possible that our respondents did not witness these deaths, which makes the violence we study different from prior studies like Blattman (2009).
}

more than four family members had died. ${ }^{16}$ This provides us with an ordinal measure that captures the intensity of victimization the respondent suffered above and beyond the violence of deportation.

To reiterate, the use of this measure assumes that additional violence has incremental effects on its victims. Since we are comparing deportees to one another, our analysis leverages the additional violence some suffered and others did not. Our ordinal measure also assumes that victimization is not binary, but varies in intensity. ${ }^{17}$

Importantly, our measure also relies on the ability of our respondents to reliably recall and truthfully convey the deportation events. Given the absence of documentation about individual deaths, we lack objective measures of the intensity of violence suffered by Crimean Tatars. This problem affects most studies of political violence, particularly when violence is perpetrated by the very state in charge of recordkeeping. Our approach follows the standard practice in individual-level studies of relying on self-reports (e.g., Blattman 2009; Canetti-Nisim et al. 2009). However, doing so may be less problematic in our case. For one, we rely only on the self-reports of the first-generation respondents who actually lived through the violence, ${ }^{18}$ not their descendants. We also use a very specific question to measure the intensity of victimization. ${ }^{19}$ In most interviews, this question elicited specific

\begin{abstract}
${ }^{16}$ Only two first-generation respondents did not answer this question, allaying concerns about fear or shame biasing our measure. Table A4 reports the distribution of responses. Seventy-two percent said at least one of their family members died. There is no clear way to compare this figure to actual deaths because of the wide range between official statistics and Crimean Tatar claims and because the deaths might not have been equally distributed across families. Still, if we assume an average household of five people and an average death rate of $25 \%$, the probability of a household having at least one death would be $76 \%$.

${ }^{17}$ We also estimated our models using a dichotomous variable that distinguishes respondents whose grandparent did not lose any family members during deportation from those whose grandparent lost one or more (Table A24). Doing this reduces our precision, but the results are substantively similar. We also replicated our analyses with dummy variables for the ordinal values of our measure of victimization (Table A25), revealing little evidence of nonlinearities.

\footnotetext{
${ }^{18}$ Some of our first-generation respondents were very young children during the deportation. But limiting our analysis to those families whose first-generation respondent was at least 6 years old in 1944 does not substantively change our results (Table A14).
}

${ }^{19}$ We also asked whether any of the respondent's close relatives had been shot or arrested by Soviet authorities and whether any relatives went missing. While these items measure other types of violence, they are less reliable measures of victimization. Individuals could have been prosecuted by the Soviet regime for actual crimes unconnected with their status as deportees. Crimean Tatars also went missing because they were unfamiliar with the local environment, circumstances that deportees rarely blamed on the state. Moreover, arrests and disappearances may well have been politically targeted. 


\section{FIGURE 1 Endogeneity Tests}

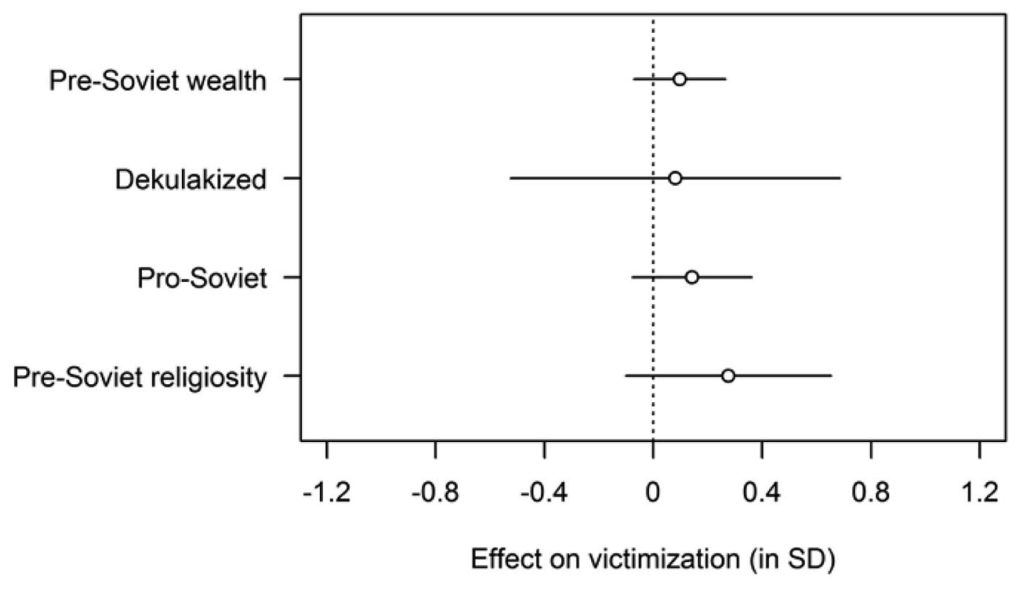

Note: Values represent changes in the degree of victimization, based on shifting each variable from its sample 25 th to 75 th percentile, with all other variables held at their sample means. These predicted effects are expressed in standard deviations of our measure of victimization. Solid lines show the simulated $95 \%$ confidence interval. Black dots represent values that are significant at 95\% confidence, and white dots indicate those that fall short of that threshold. These predicted values are based on the linear regression model presented in Table A6. The model includes statistically insignificant dummy variables for predeportation region and deportation destination.

accounts of the relatives the respondent lost and the circumstances of their deaths. Although traumatic memories are always subjective-and we cannot rule out recall biases - we think our measure is as reliable as possible.

We use this measure to study the effects of ancestor victimization on descendants' identities, attitudes, and behaviors. But note that our sample design means that we only know the intensity with which one grandparent of each third-generation respondent was victimized. This effectively assumes that a third-generation respondent's other grandparents did not lose close relatives during and shortly after deportation, meaning that we are underestimating the true intergenerational effects of victimization.

Our ability to identify the effect of violence hinges on the assumption that the death of family members was plausibly exogenous to the prior political identities of survivors. To test this assumption, we asked first-generation respondents about their family's wealth, religiosity, attitudes toward the Soviet Union, and persecution at the hands of state authorities prior to deportation. ${ }^{20}$ Figure 1

We thus chose to use just the single item on close relatives' deaths, which has the further advantage that it captures a kind of violence that generalizes far beyond this case.

\footnotetext{
${ }^{20}$ To measure exposure to state persecution, we ask whether the family had been dekulakized in the 1930s, that is, declared wealthy and stripped of assets or subjected to harassment and arrests.
}

suggests that our assumption holds. When we regress our measure of victimization on these predeportation variables, we find no statistically significant correlations and, at best, small substantive effects. ${ }^{21}$ To facilitate comparisons, this and subsequent figures show the predicted effect of shifting each variable along its interquartile range-that is, changing its value from the 25 th to the 75 th percentile. Because our measures come from survey items with different response scales or from factored indexes, we report effects in terms of standard deviations for comparability. Figure 1 shows how the interquartile range of each predeportation variable affects the victimization variable in terms of standard deviations of change. All the relationships are small and statistically indistinguishable from zero.

Our survey included items that measure the core identities we expect to be shaped by the trauma of losing close relatives during the deportation. We asked respondents a series of questions to determine the intensity of their attachment to the Crimean Tatars as a social group, their association of that group with victimhood, and their perception of the threat posed by Russia. We measure the respondents' ingroup attachment as the difference between how trusting they are of other Crimean Tatars

\footnotetext{
${ }^{21}$ To simplify interpretation and comparison, this and subsequent analyses use linear regression models. Our results are robust to using probit or ordered probit models (Table A11).
} 
and how trusting they are of ethnic Russians. ${ }^{22}$ To measure whether victimhood is part of their social identity, we asked whether they believed Crimean Tatars were victims of the Soviet state. We also measured threat perception by asking respondents whether they felt fear when Russia annexed Crimea in early 2014 and what they feared. ${ }^{23}$ We expect these three variables to take on higher values among those first-generation respondents who experienced greater victimization. We also expect higher values on these measures to persist across generations.

We further hypothesized that ancestor victimization would affect the contemporary political attitudes and behaviors of the grandchildren of respondents who were more victimized. In particular, we expect that the grandchildren of those more intensely victimized will embrace radical Islam and religiosity, be more protective of Crimean Tatar political interests and more hostile toward the Russian state, and be more active politically. ${ }^{24}$

To measure religiosity, we asked respondents how regularly they engage in various religious activities, such as reading the Quran. Support for radical Islam is measured via questions about respondents' attitudes toward Sharia law; their views about Hizb utTahrir, a Central Asian radical Islamist organization active among Crimean Tatars; and their attitudes toward the radical Wahhabi movement within Sunni Islam. To quantify support for Crimean Tatar political issues, we constructed an index of feeling thermometers regarding three prominent Crimean Tatar political leaders (Mustafa Dzhemilev, Refat Chubarov, and Remzi Il'iasov), ${ }^{25}$ and we measured whether respondents observe the Crimean Tatar Flag Day, a communal celebration of Crimean Tatar political and cultural identity.

${ }^{22}$ In our pilot study, we found little variation in attachments using the standard self-identification scale. To achieve variation, we chose the trust differential, a measure that adheres closely to the notion of identity as a sense of "groupness" (Abdelal et al. 2009). Table A7 shows that by this measure, Crimean Tatars who more closely identify with their ethnic group are more likely to watch the Crimean Tatar television station, speak Crimean Tatar at home, and oppose mixed marriages with other ethnicities. These correlations give us confidence in our measure.

${ }^{23}$ The threat perception variable is measured on a 4-point scale that runs from no fear (0) to fear of interethnic disturbances (1) to fear of possible targeted suspension of civil and political rights (2) to fear of deportation and mass arrests (3).

${ }^{24}$ In order to reduce measurement error, where possible we included multiple items in our survey to capture the same latent attitude. In our analysis, we combine these items into factored indexes. Details are provided in the supporting information.

${ }^{25}$ Dzhemilev was a Soviet dissident and longtime head of the Crimean Tatar popular assembly, Chubarov was his successor, and Il'iasov was deputy speaker of Crimea's regional parliament.
We developed three measures of attitudes toward Russia: one based on whether the respondent said that Chechens fighting the Russian state were freedom fighters and not radicals (a view that is contrary to the official Russian narrative), a second asking whether they supported the annexation of Crimea by Russia, and an index of pro-Russia vote choices in the annexation referendum and the September 2014 local election. To measure political engagement, we constructed two indexes: one based on whether respondents participated in recent elections - the referendum on Crimea's annexation and the local election - and a second using questions that asked whether they would be willing to participate in various political activities. ${ }^{26}$

\section{Ancestor Victimization and Political Identities, Attitudes, and Behaviors}

The results of our analyses linking ancestral exposure to political violence and contemporary identities, attitudes, and behaviors are summarized in Figure $2 .{ }^{27}$ We find that the intensity of victimization of the first generation substantially shapes the identities, attitudes, and behaviors of their grandchildren. An interquartile shift in the intensity of victimization changes most of our outcomes by between a quarter and a half of a standard deviation. These are substantial effects. In a normally distributed variable, $68 \%$ of the variation lies within one standard deviation, 95\% within two standard deviations. It seems quite remarkable that something people experienced more than 70 years ago changes their grandchildren's attitudes by a quarter of a standard deviation.

Beginning at the top of the figure, we see that firstgeneration victimization strengthens third-generation descendants' attachment to their ethnic group and makes them more likely to self-identify as victims and to perceive Russia as a threat. ${ }^{28}$ This is consistent with our expectation that violence fosters ethnic parochialism, which is then transmitted across generations.

\footnotetext{
${ }^{26}$ We also asked respondents whether they had participated in these same political activities, and our results with this measure are similar (Table A8).

${ }^{27}$ Our findings are substantively robust to including predeportation control variables in these models (Table A9). In two cases, the smaller sample makes our estimates less precise, but the coefficients are almost identical.

${ }^{28}$ These identities are not consistently associated with reporting more family members' having been arrested, executed, or disappeared (Table A19). This gives us confidence that self-reports of family member deaths are not biased by ingroup attachment.
} 


\section{FIGURE 2 Effects of First-Generation Victimization on Third-Generation Attitudes and Behavior}

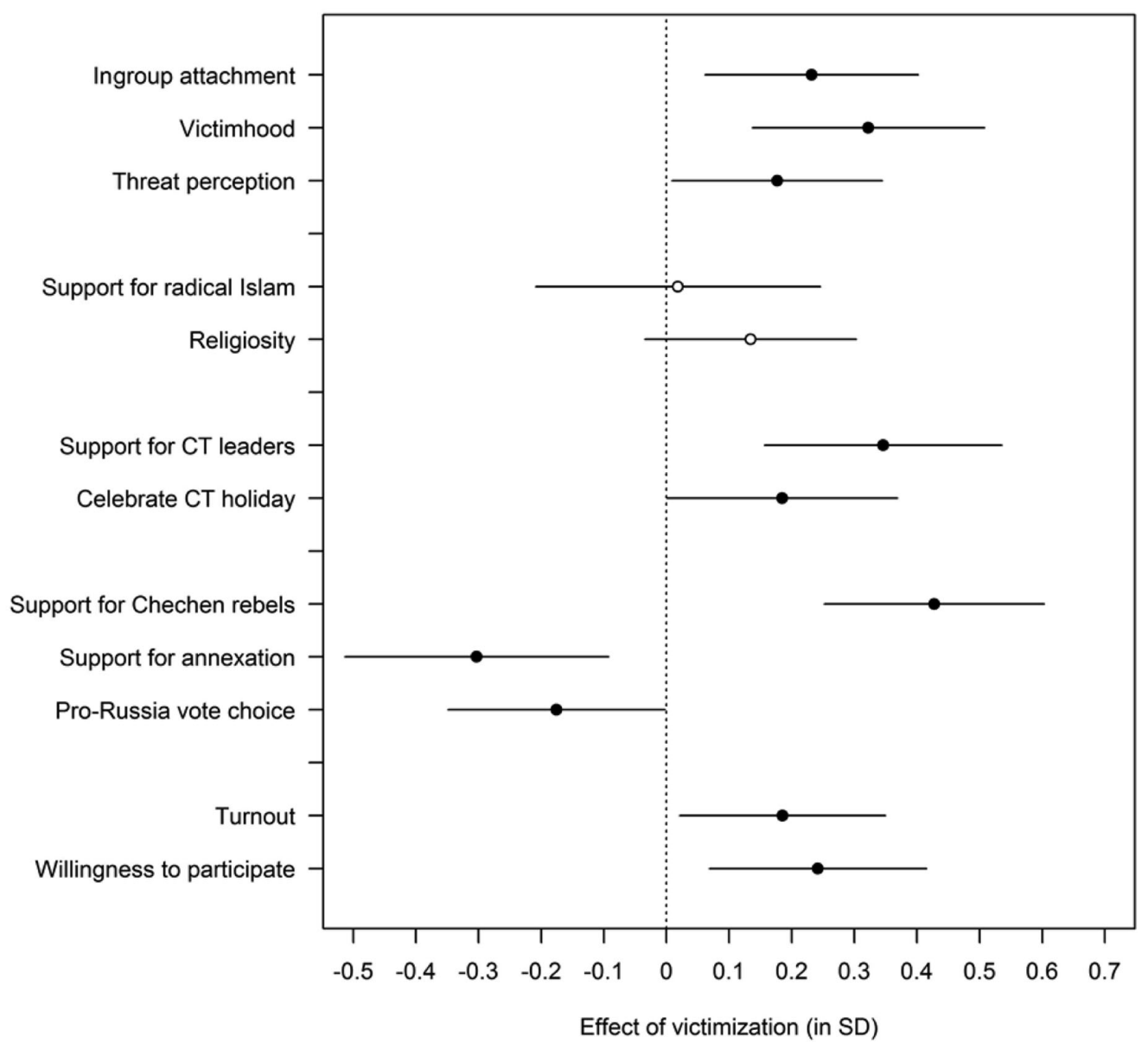

Note: $\mathrm{CT}=$ Crimean Tatar. Values represent changes in the magnitude of each dependent variable, based on shifting the degree of victimization from its sample 25th to 75 th percentile. These predicted effects are expressed in standard deviations of the dependent variable. Solid lines show the simulated $95 \%$ confidence interval. Black dots represent values that are significant at $95 \%$ confidence, and white dots indicate those that fall short of that threshold. These predicted values are based on the regression models presented in Table A8.

In contrast to the conventional wisdom linking repression to radicalization and trauma to religiosity, we did not find evidence that the descendants of those more intensely victimized are more religious or more supportive of radical forms of Islam. This may be due to the fact that the version of Islam practiced by Crimean Tatars is fairly secular, so much so that even a family grievance against state authorities does not result in religious radicalization. Our results may also suggest that the links between repression and radicalization only apply to the victims themselves and are not transmitted across generations.

When it comes to attitudes about Crimean Tatar politics, young Crimean Tatars from more intensely victimized families are significantly more supportive of the group's political positions. The descendants of victims are more likely to support Crimean Tatar political leaders and more likely to celebrate the Crimean Tatar Flag Day.

Some of the most interesting findings, and also those with the largest effects, concern attitudes toward Russia, viewed by Crimean Tatars as the successor to the repressive system that systematically perpetrated violence against their community. In a sign that victims' descendants are especially motivated to fight against the perpetrator state, a shift on first-generation victimization along the interquartile range increases third-generation respondents' support for Chechen and Dagestani separatists by nearly half a standard deviation. Likewise, thirdgeneration respondents from families especially victimized by the deportation are less likely to approve of Russia's 
annexation of Crimea and less likely to support Russia's ruling political party in the local election.

Finally, third-generation respondents with more intensely victimized ancestors are consistently more politically engaged than their peers. They report a greater willingness to participate in political activities in the future and are more likely to have voted in the Russia-backed Crimea referendum of March 2014 and in the local elections of September 2014. Interestingly, the descendants of more intensely victimized Crimean Tatars were more likely to participate in these elections even though the Crimean Tatar community generally boycotted both of these political events, especially the March referendum. Although these results are consistent with studies that find an effect of violence on political engagement among the victims themselves, they highlight both the intergenerational effect of violence and the fact that this participation seems motivated by opposition to potential renewed persecution, not by posttraumatic growth.

\section{Tracing Family Transmission}

Our research design allows us to identify the effect that violence experienced by the first generation has on the political identities, attitudes, and behaviors of the third generation. But in addition to these main results, we also want to leverage our data to study the mechanism of family transmission.

We begin by interrogating the connection between victimization experiences and core political identities-self-identification with one's ethnic group, self-perception as a victim, and heightened threat perception-among first-generation respondents. If our hypothesis that violence shapes especially these core identities is right, we should observe it among the survivors themselves. Our results are reported in Figure 3. We find consistently strong effects of victimization on these identities.

Next, we want to know whether these effects are transmitted across generations, as we hypothesized. To study family transmission, we examine whether ingroup attachment, self-identification as a victim of the political system, and threat perception are correlated across generations within each family. Figure 4 demonstrates that they are. Unsurprisingly, the correlations appear strongest between immediately adjacent generationsfrom first to second generation and from second to third generation-although we find some persistence when we compare grandparents directly to grandchildren.

\section{FIGURE 3 Effects of Victimization on Identities among First Generation}

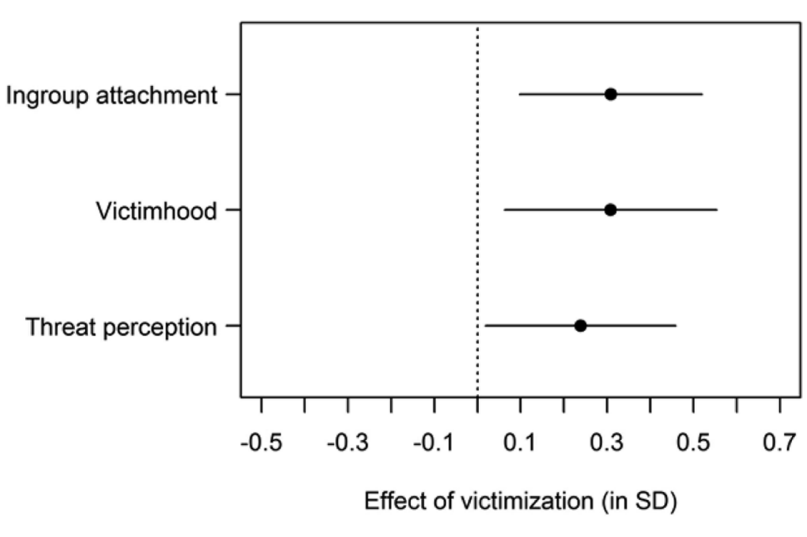

Note: Values represent changes in the magnitude of each dependent variable, based on shifting the degree of victimization from its sample 25th to 75th percentile. These predicted effects are expressed in standard deviations of the dependent variable. Solid lines show the simulated 95\% confidence interval. Black dots represent values that are significant at $95 \%$ confidence, and white dots indicate those that fall short of that threshold. These predicted values are based on the regression models presented in Table A20.

Self-identification as a victim is most strongly transmitted between the first generation, who had personal experience of political violence, and their children. In contrast, the second generation appears to be most effective at transmitting ingroup attachment. In general, between $30 \%$ and $50 \%$ of the variation in these variables seems to correlate across adjacent generations. $^{29}$

Of course, these estimates are only correlations. A major challenge in studies of family socialization, which typically rely on similar intergenerational correlations, is that it can be difficult to distinguish socialization from the fact that parents and their children tend to resemble each other in other ways. Parents and their offspring may identify in similar ways, but that may be because they arrived at the same identities independently-for instance, as a result of their similar socioeconomic status. But ours is a particularly good case for inferring family transmission from correlations because the second and third generations in our sample did not inherit wealth or status from their ancestors. Thus, there are good reasonsstronger than in most studies of family socializationto think that the persistence of identities and threat

\footnotetext{
${ }^{29}$ These estimates suggest that within the next two generations, Crimean Tatar families will no longer be distinguishable by the number of close relatives their ancestors lost during the deportation. Note, however, that this is an underestimate.
} 


\section{FIGURE 4 Intergenerational Persistence of Identities}

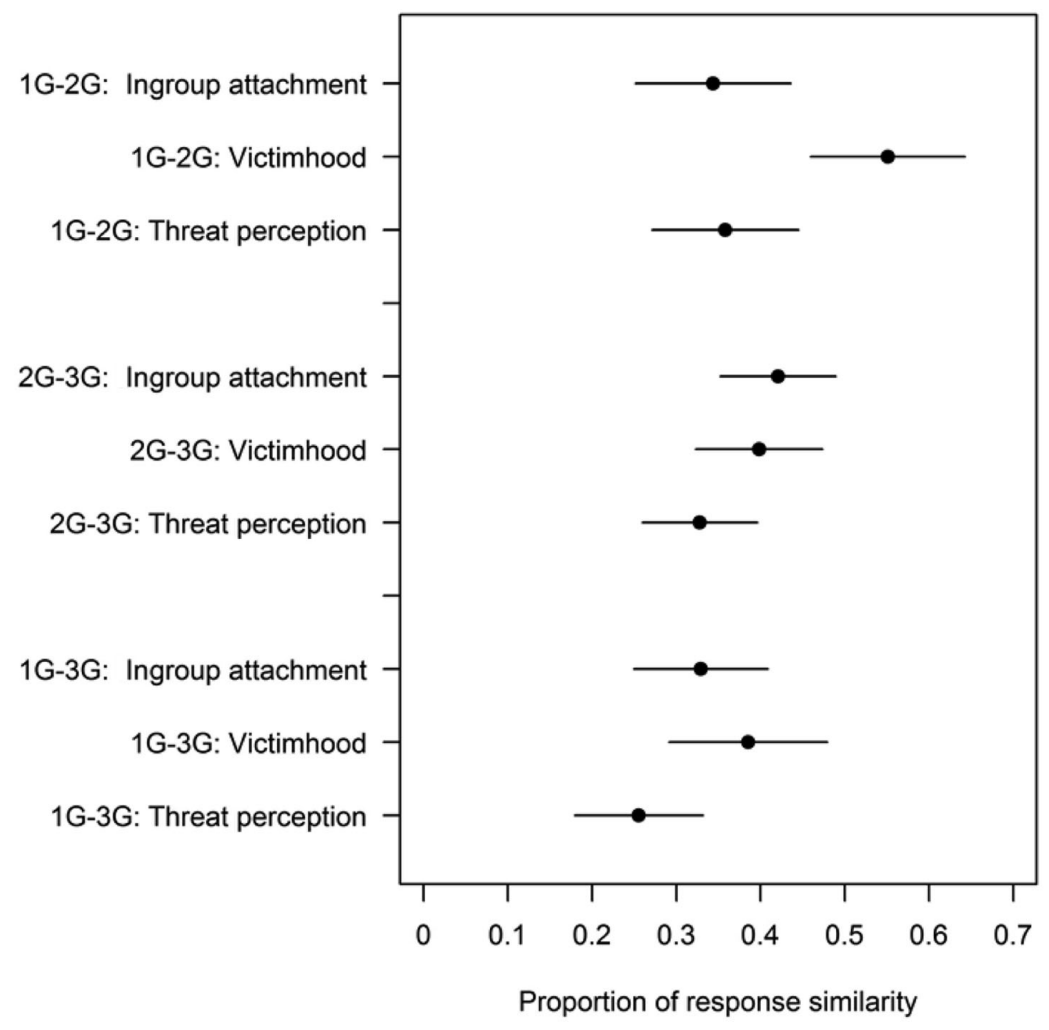

Note: Values represent the proportion of variation that is similar across pairs of generations. Solid lines show the simulated $95 \%$ confidence interval. All estimates are statistically significant at $95 \%$ confidence. These estimates are based on the regression models presented in Table A21.

perception in these cases is the result of family transmission and not of some other factor. ${ }^{30}$

Aside from these intergenerational correlations, another way of studying family transmission could be to try to observe the mechanisms of transmission. Doing this requires engaging in mediation analysis, which poses both logical and empirical challenges (Green, Ha, and Bullock 2010), so our evidence on this score should be treated as merely suggestive. One way to study the mechanism of family transmission would be to show that the relationships between victimization and political identities, attitudes, and behaviors are conditioned by factors that might intensify family transmission. We asked our third-generation respondents how often they discussed the deportation experiences with their parents and grandparents while growing up. In Figure 5, we interact the frequency of these family discussions with our

\footnotetext{
${ }^{30}$ Our main results are also robust to controlling for (posttreatment) third-generation demographics (Table A10), bolstering our confidence that family transmission is at work.
}

measure of victimization. ${ }^{31}$ Although these interaction effects do not always reach statistical significance, the estimates generally suggest that more family discussion intensifies the effect of victimization. In other words, where family transmission is strongest, the effect of ancestor victimization on third-generation respondents' contemporary identities, attitudes, and behaviors is also most intense.

Another suggestive way to study the mechanism of family transmission is to see whether including mediating variables in our regressions attenuates the effect of victimization. In the supporting information (Table A23), we did this by adding the identity measures - ingroup attachment, victimhood, and threat perception-into our main models. We found that the effect of ancestor victimization on almost all of our measures of contemporary attitudes and behaviors seems substantially, if not entirely, mediated by inherited political identities. Like our analysis

\footnotetext{
${ }^{31}$ Like any mediating variable, family discussion is posttreatment and potentially endogenous to victimization. This is another reason that our mediation analysis should only be considered suggestive.
} 
FIGURE 5 Conditioning Effect of Family Discussion
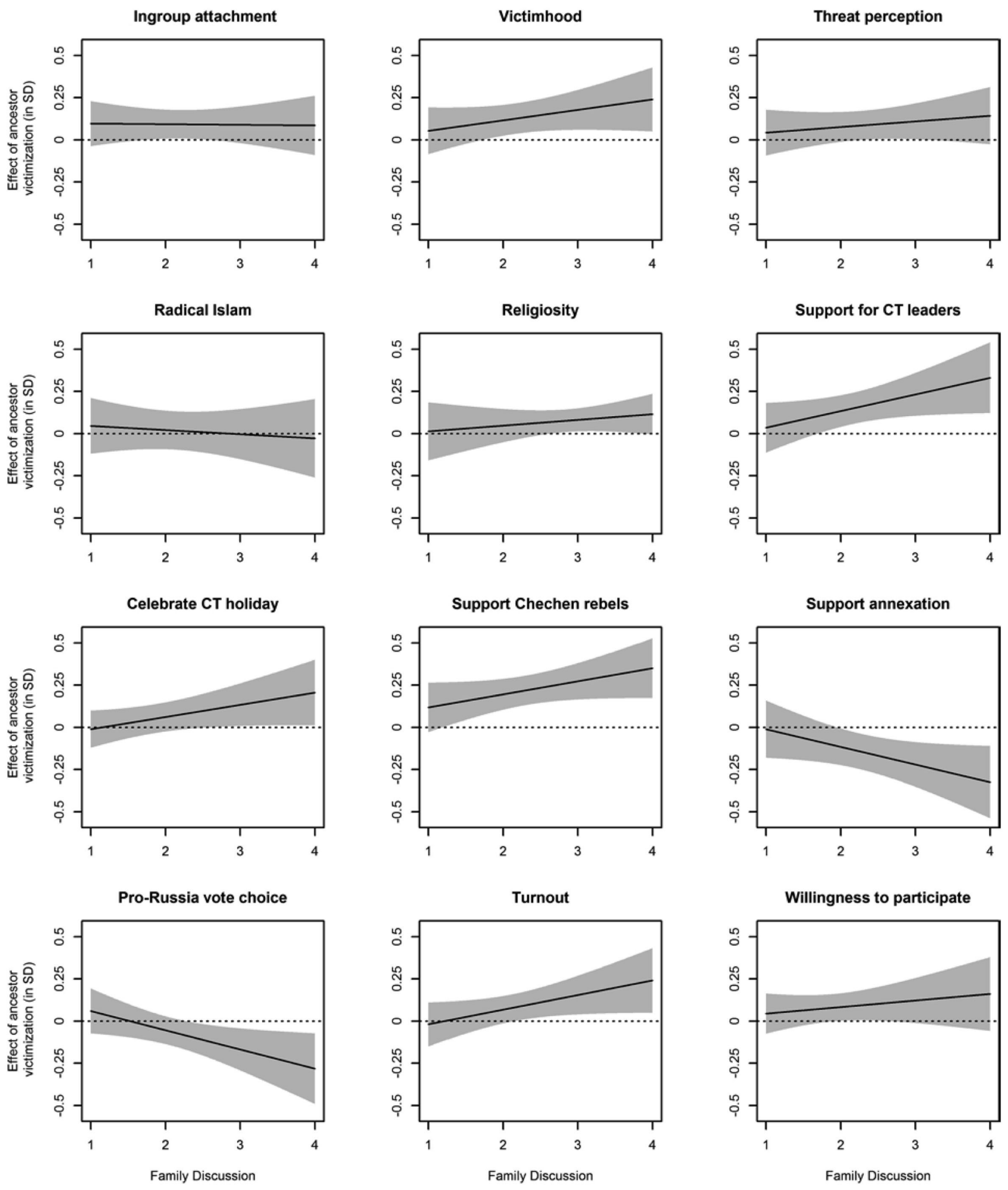

Note: $\mathrm{CT}=$ Crimean Tatar. Values represent estimated effects of ancestor victimization on each dependent variable at varying frequency of family discussion about deportation. Shaded regions represent 95\% confidence intervals. These estimates are based on regression models reported in Table A22. 
with family discussion, this evidence is merely suggestive, but it is heartening that these various efforts at studying the mechanism of family transmission generally point in the direction we expected.

\section{Legacies of Political Violence}

Violence leaves lasting legacies that shape political attitudes and behaviors across generations. Our multigenerational survey of Crimean Tatars reveals not only that political violence shapes the political identities of victims but also that these are transmitted to their descendants through the family. In turn, these identities shape the attitudes and behaviors of descendants of victims of political violence. Crimean Tatars whose ancestors suffered additional violence above the baseline of deportation are today more supportive of their group's position on political issues, more hostile toward Russian authorities and Russians generally, and more politically engaged. Even though the violence we study was perpetrated over 70 years ago, it still substantially affects political views and behaviors. These findings have important implications for how we think about transitional justice. They may also explain why we see populations trapped in cycles of violence, the result of ethnic parochialism and animosities transmitted from generation to generation.

Our findings are limited to a particular population sampled during a peculiar political moment. Russia's annexation of Crimea may have made Crimean Tatars more fearful, intensifying the effects of deportation experiences on contemporary preferences. If Russia's annexation made all Crimean Tatars equally more fearful, that would not affect our results since our comparison is among Crimean Tatar families. It is possible that grandchildren whose grandparents lost more relatives during the deportation became more fearful of Russia postannexation than those whose grandparents lost fewer relatives. But this would still mean that somethinghowever latent-had been transmitted to members of the youngest generation from their grandparents, making them more responsive to the annexation. We can only speculate about whether we would have been able to observe that latent characteristic prior to the annexation. But the question this raises is under what circumstances we would observe effects similar to those we found among Crimean Tatars. Like all questions of generalizability, this one can only be answered definitively through additional studies of other cases.

A priori, there are good reasons to expect our findings to obtain beyond the Crimean Tatar population. The kind of violence we study is, unfortunately, all too frequent. Deportations like that of Crimean Tatars, and resultant loss of family members, were quite common across Europe in the interwar period, as well as during and after World War II. In the Soviet Union, mass deportations affected Azeris, Armenians, Chechens, Ingush, Koreans, Ukrainians, and inhabitants of the Baltics, to name the more prominent cases. Our study, though, focused not on the effect of deportations per se, but on the effects associated with the death of a close relative during a deportation. And losing family members is common both during conflicts and under authoritarian rule. It is possible that something about this particular context amplifies these effects, but that is something we can only determine through further research. In future work, we plan to study the lasting effects of civil war violence in Guatemala and state-sponsored genocide in Cambodia.

Our study also offers an innovative empirical strategy for exploring the effects of political violence. One challenge facing scholarship in this field is that violence is often systematically targeted. That makes it difficult for scholars to make inferences about the consequences of political violence. This study highlights that even in cases where some violence (the deportation of all Crimean Tatars) is systematic, additional forms of violence (the death of relatives) may be meted out in plausibly exogenous ways. Scholars can leverage these exogenous variations in the intensity of violence to help us understand the persistent effects of political violence.

The growing body of research on political violence is only beginning to engage with the question of persistent, long-term effects of violence, and this article is part of that effort. Research on historical legacies has theorized about the important role families play in transmitting legacies across generations, but it has largely failed to isolate this role empirically. As more scholars become interested in studying historical legacies, we will need to turn to individual-level evidence to understand how they persist over time. Our study shows that multigenerational surveys offer important empirical advantages.

Of course, we are not the first to highlight the important role of family transmission in political identities. But existing studies of family socialization in political science have almost exclusively focused on partisan identities in the advanced democracies. A whole host of experiences that are uncommon in advanced democracies-including political violence-is therefore largely missing from this body of work. As a result, we still know little about what kinds of identities and perceptions parents transmit to their children, how parents' personal experiences affect the political identities of their children, and precisely how family transmission works. These unanswered questions 
are important if we are to continue to build our understanding of political identities, attitudes, and behavior.

\section{References}

Abdelal, Rawi, Yoshiko M. Herrera, Alastair Iain Johnston, and Rose McDermott, eds. 2009. Measuring Identity. Cambridge: Cambridge University Press.

Acemoglu, Daron, Simon Johnson, and James Robinson. 2001. "The Colonial Origins of Comparative Development: An Empirical Investigation." American Economic Review 91(5): 1369-1401.

Aguilar, Paloma, Laia Balcells, and Héctor Cebolla-Boado. 2011. "Determinants of Attitudes toward Transitional Justice: An Empirical Analysis of the Spanish Case." Comparative Political Studies 44(10): 1397-1430.

Aleshka, Aliaksandr, Volodymyr Ilnytskyi, Vasili Bondar, and Bekir Umerov, trans. 2010. Crimean Tatars. Frankfurt an der Oder, Germany: Institute for Applied History.

Balcells, Laia. 2012. "The Consequences of Victimization on Political Identities: Evidence from Spain.” Politics \& Society 40(3): 311-47.

Bauer, Michal, Christopher Blattman, Julie Chytilová, Joseph Henrich, Edward Miguel, and Tamar Mitts. 2016. "Can War Foster Cooperation?” Journal of Economic Perspectives 30(3): 249-74.

Bauer, Michal, Alessandra Cassar, Julie Chytilová, and Joseph Henrich. 2014. "War's Enduring Effects on the Development of Egalitarian Motivations and In-Group Biases." Psychological Science 25(1): 47-57.

Beber, Bernd, Philip Roessler, and Alexandra Scacco. 2014. "Intergroup Violence and Political Attitudes: Evidence from a Dividing Sudan." Journal of Politics 76(3): 649-65.

Bekirova, Gulnara. 2004. Krymskotatarskaia Problema v SSSR, 1944-1991. Simferopol: Odzhak.

Bellows, John, and Edward Miguel. 2009. "War and Local Collective Action in Sierra Leone." Journal of Public Economics 93(11-12): 1144-57.

Benard, Cheryl. 1994. "Rape as Terror: The Case of Bosnia." Terrorism and Political Violence 6(1): 29-43.

Berrebi, Claude, and Estaban F. Klor. 2008. "Are Voters Sensitive to Terrorism? Direct Evidence from the Israeli Electorate." American Political Science Review 102(3): 279301.

Bisin, Alberto, Giorgio Topa, and Thierry Verdier. 2004. "Religious Intermarriage and Socialization in the United States." Journal of Political Economy 112(3): 615-64.

Bisin, Alberto, and Thierry Verdier. 2000. "Beyond the Melting Pot': Cultural Transmission, Marriage, and the Evolution of Ethnic and Religious Traits." Quarterly Journal of Economics 115(3): 955-88.

Bisin, Alberto, and Thierry Verdier. 2001. "The Economics of Cultural Transmission and the Dynamics of Preferences." Journal of Economic Theory 97(2): 298-319.

Blattman, Christopher. 2009. "From Violence to Voting: War and Political Participation in Uganda." American Political Science Review 103(2): 231-47.
Blattman, Christopher, and Edward Miguel. 2010. "Civil War." Journal of Economic Literature 48(1): 3-57.

Bugai, Nikolai. 2002. Deportatsiia Narodov Kryma. Moscow: INSAN.

Bugai, Nikolai. 2004. Deportatsiia Narodov. Vol. 2. Moscow: Nauka.

Canetti-Nisim, Daphna, Eran Halperin, Keren Sharvit, and Stevan E. Hobfoll. 2009. "A New Stress-Based Model of Political Extremism: Personal Exposure to Terrorism, Psychological Distress, and Exclusionist Political Attitudes." Journal of Conflict Resolution 53(3): 363-89.

Cassar, Alessandra, Pauline Grosjean, and Sam Whitt. 2013. "Legacies of Violence: Trust and Market Development." Journal of Economic Growth 18(3): 285-318.

Chen, Yung Y., and Harold G. Koenig. 2006. "Traumatic Stress and Religion: Is There a Relationship? A Review of Empirical Findings." Journal of Religion and Health 45(3): 371-81.

Darden, Keith, and Anna Grzymala-Busse. 2006. "The Great Divide: Literacy, Nationalism, and the Communist Collapse." World Politics 59(1): 83-115.

Fearon, James D., Macartan Humphreys, and Jeremy M. Weinstein. 2009. "Can Development Aid Contribute to Social Cohesion after Civil War? Evidence from a Field Experiment in Post-Conflict Liberia." American Economic Review Papers and Proceedings 99(2): 287-91.

Gabrielian, Oleg, Sergei Efimov, Viacheslav Zarubin, Aleksandr Kislyi, Andrei Mal'gin, Andrei Nikiforov, Vladimir Pavlov, and Vadim Petrov. 1998. Krymskie Repatrianty. Simferopol, Russia: Amena.

Gilligan, Michael J., Benjamin J. Pasquale, and Cyrus Samii. 2014. "Civil War and Social Cohesion: Lab-in-the-Field Evidence from Nepal." American Journal of Political Science 58(3): 604-19.

Green, Donald P., Shang E. Ha, and John G. Bullock. 2010. "Enough Already about 'Black Box' Experiments: Studying Mediation Is More Difficult Than Most Scholars Suppose." Annals of the American Academy of Political and Social Science 628(1): 200-208.

Grosjean, Pauline. 2014. "Conflict and Social and Political Preferences: Evidence from World War II and Civil Conflict in 35 European Countries." Comparative Economic Studies 56(3): 424-51.

Grossman, Guy, Devorah Manekin, and Dan Miodownik. 2015. "The Political Legacies of Combat: Attitudes toward War and Peace among Israeli Ex-Combatants." International Organization 69(4): 981-1009.

Hobfoll, Steven E., Daphna Canetti-Nisim, and Robert J. Johnson. 2006. "Exposure to Terrorism, Stress-Related Mental Health Symptoms, and Defensive Coping among a Nationally Representative Sample in Israel." Journal of Consulting and Clinical Psychology 74(2): 207-18.

Horgan, John. 2008. "Profiles to Pathways and Roots to Routes: Perspectives from Psychology on Radicalization into Terrorism." Annals of the American Academy of Political and Social Science 618: 80-94.

Jennings, M. Kent, and Richard G. Niemi. 1981. Generations and Politics. Princeton, NJ: Princeton University Press.

Jennings, M. Kent, Laura Stoker, and Jake Bowers. 2009. "Politics across Generations: Family Transmission Reexamined." Journal of Politics 71(3): 782-99. 
Johnson, Howard, and Andrew Thompson. 2008. "The Development and Maintenance of Post-Traumatic Stress Disorder (PTSD) in Civilian Adult Survivors of War Trauma and Torture: A Review." Clinical Psychology Review 28(1): 3647.

Lev-Wiesel, Rachel. 2007. "Intergenerational Transmission of Trauma across Three Generations: A Preliminary Study." Qualitative Social Work 6(1): 75-94.

Lupu, Noam, and Susan C. Stokes. 2010. "Democracy, Interrupted: Regime Change and Partisanship in TwentiethCentury Argentina.” Electoral Studies 29(1): 91-104.

MacFarquhar, Roderick, and Michael Schoenhals. 2008. Mao's Last Revolution. Cambridge, MA: Belknap Press.

McCauley, Clark, and Sophia Moskalenko. 2008. "Mechanisms of Political Radicalization: Pathways toward Terrorism.” Terrorism and Political Violence 20(3): 415-33.

Mollison, Denis, ed. 1995. Epidemic Models. New York: Cambridge University Press.

Nalepa, Monika. 2012. “Tolerating Mistakes: How Do Popular Perceptions of Procedural Fairness Affect Demand for Transitional Justice?" Journal of Conflict Resolution 56(3): 490-515.

Nunn, Nathan, and Leonard Wantchekon. 2011. "The Slave Trade and the Origins of Mistrust in Africa.” American Economic Review 101(7): 3221-52.

Peisakhin, Leonid. 2012. "Long Shadow of the Past: Identity, Norms, and Political Behavior." Ph.D. dissertation, Yale University. http://gradworks.umi.com/35/25/3525233.html.

Pohl, J. Otto. 1997. The Stalinist Penal System. Jefferson, NC: McFarland.

Rozenas, Arturas, Sebastian Schutte, and Yuri Zhukov. 2017. "The Political Legacy of Violence: The Long-Term Impact of Stalin's Repression in Ukraine." Journal of Politics.

Uehling, Greta Lynn. 2004. Beyond Memory. New York: Palgrave Macmillan.

Voigtländer, Nico, and Hans-Joachim Voth. 2012. "Persecution Perpetuated: The Medieval Origins of Anti-Semitic Violence in Nazi Germany." Quarterly Journal of Economics 127(3): 1339-92.

Walter, Barbara F. 2004. "Does Conflict Beget Conflict? Explaining Recurring Civil War." Journal of Peace Research 41(3): 371-88.

Walter, Barbara F., and Jack Snyder, eds. 1999. Civil Wars, Insecurity, and Intervention. New York: Columbia University Press.

Weiss, Micha, and Sima Weiss. 2000. "Second Generation to Holocaust Survivors: Enhanced Differentiation of Trauma Transmission." American Journal of Psychotherapy 54(3): 372-85.

Whitt, Sam, and Rick K. Wilson. 2007. "The Dictator Game: Fairness and Equity in Postwar Bosnia." American Journal of Political Science 51(3): 655-68.

Williams, Brian Glynn. 2016. The Crimean Tatars. Oxford: Oxford University Press.

Wittenberg, Jason. 2006. Crucibles of Political Loyalty. Cambridge: Cambridge University Press.

Wood, Elisabeth Jean. 2003. Insurgent Collective Action and Civil War in El Salvador. Cambridge: Cambridge University Press.
Wood, Elisabeth Jean. 2006. "Variation in Sexual Violence during War." Politics and Society 34(3): 307-41.

Zaloznaya, Marina, and Theodore P. Gerber. 2012. "Migration as Social Movement: Voluntary Group Migration and the Crimean Tatar Repatriation." Population and Development Review 38(2): 259-84.

Zemskov, Viktor. 1991. "GULAG: A Historic-Sociological Dimension.” Sotsiologicheskie Issledovaniia 6(7): 10-27.

Zuckerman, Alan S., Josip Dasovic, and Jennifer Fitzgerald. 2007. Partisan Families. Cambridge: Cambridge University Press.

\section{Supporting Information}

Additional Supporting Information may be found in the online version of this article at the publisher's website:

Table A1: Location of Crimean Tatars on January 1, 1953 (Soviet sources)

Table A2: Survey sample characteristics, by generation

Table A3: Descriptive statistics

Table A4: Distribution of intensity of victimization

Table A5: Relationship between geographic region and ancestor victimization

Table A6: Endogeneity tests

Table A7: Correlates of in-group attachment measure

Table A8: Effects of first-generation victimization on third-generation attitudes and behaviors

Table A9: Effects of first-generation victimization on third-generation identities, attitudes, and behaviors, with pre-deportation controls

Table A10: Effects of first-generation victimization on third-generation identities, attitudes, and behaviors, with third-generation demographic controls

Table A11: Effects of first-generation victimization on third-generation identities, attitudes, and behaviors probit models

Table A12: Effects of first-generation victimization on third-generation identities, attitudes, and behaviors, excluding families deported to Russia

Table A13: Effects of first-generation victimization on third-generation identities, attitudes, and behaviors, excluding 3G born before Soviet Union collapse

Table A14: Effects of first-generation victimization on third-generation identities, attitudes, and behaviors, excluding $1 \mathrm{G}$ less than six years old in 1944

Table A15: Effects of first-generation victimization on third-generation identities, attitudes, and behaviors, among families living in different settlements

Table A16: Effects of first-generation victimization on third-generation identities, attitudes, and behaviors, among families interviewed on the same day 
Table A17: Effects of first-generation victimization on third-generation identities, attitudes, and behaviors, among families interviewed within one day of each other Table A18: Effects of first-generation victimization on third-generation identities, attitudes, and behaviors, among families interviewed within two days of each other Table A19: Association between identities and reports of other violence, among first generation

Table A20: Effects of victimization on attitudes among first generation

Table A21: Intergenerational persistence of victimization effects
Table A22: Effects of first-generation victimization on third-generation identities, attitudes, and behaviors, conditioned by family discussion

Table A23: Implicit mediation analysis

Table A24: Effects of first-generation victimization on third-generation identities, attitudes, and behaviors with dichotomous measure of victimization

Table A25: Effects of first-generation victimization on third-generation identities, attitudes, and behaviors with dummy variables for levels of victimization

Survey Methodology

Survey Question Wording 